\title{
Contact-induced linguistic innovations on the continuum of language use: The case of
French in Ontario* of language use: The case of
French in Ontario*
}

\begin{abstract}
In this paper we present a methodological approach that can be used to determine the likelihood that innovations observed in a minority language are the result of language contact. We then use this methodological approach to frame a discussion of data concerning eight innovations that can be attributed to transfer from the majority language (English) to the French of Francophones residing in the province of Ontario in Canada. This discussion shows, notably, how systemic and extra-systemic factors play a role in the emergence of these innovations. We also demonstrate that there are interesting differences in the extent to which these innovations are used across speaker groups and communities, and we argue that such differences suggest that there are thresholds of language contact associated with the emergence, or lack thereof, of particular transfer-induced innovations.
\end{abstract}

The theoretical concept of INTERFERENCE has attracted more than its share of criticism. In our view, the generally 'bad press' it has received is not due to a flaw in the theory that languages in contact may influence one another-no serious linguist would deny this fact-but rather to the lack of an adequate methodology (and to some extent also to ideological bias). For instance, in the fields of historical linguistics, minority languages, pidgins and Creoles and second language learning, one can find studies that have hastily and erroneously attributed instances of language change or interlanguage errors to language contact and that have downplayed or ignored alternative internal explanations. As a result, the factor of language contact has come to be held with much suspicion by many linguists and some have even elected to demonstrate that it plays only a marginal role as a source of variation and change in situations of societal bilingualism and language contact. While such a demonstration may be motivated on theoretical grounds, it may also reflect a hidden bias on the part of some linguists, because of the stigma that is attached to contact-induced innovations especially when they are documented in minority speech varieties. In the words of Klein-Andreu (p.c.): "the reason for [neglecting contact] is a kind of covert purism: the results of transfer are considered undesirable or 'bad'; therefore they are ignored or seriously downplayed, as a kind of courtesy to the population under study". We believe that there has been an overreaction against the notion of contact phenomena in linguistics and one of the goals of the

\footnotetext{
* We would like to thank the anonymous reviewer of a previous version of our article for his/her useful comments.
}

RAYMOND MOUGEON

Glendon College, York University

TERRY NADASDI

Modern Languages and Cultural Studies

University of Alberta

KATHERINE REHNER

Curriculum, Teaching and Learning

OISE/University of Toronto present study is to show that one can rehabilitate this concept and rekindle linguists' interest in it.

More specifically, we will draw on a large body of comparative sociolinguistic data and present a methodological approach that can be used to determine the likelihood that innovations observed in a minority language are, indeed, the result of language contact. We will then use this methodological approach to frame a discussion of data concerning eight innovations that can be attributed to transfer from the majority language of English to the French of Francophones residing in the province of Ontario in Canada. This discussion will show, notably, how systemic and extra-systemic factors play a role in the emergence of these innovations. We will also demonstrate that there are interesting differences in the extent to which these innovations are used across speaker groups and communities and that such differences suggest that there are thresholds of level of language contact associated with the emergence, or lack thereof, of particular transfer-induced innovations.

\section{Methodology}

A crucial component of our methodology is the consideration of interview data of several types. First, we make use of a large sociolinguistic corpus of speakers in a situation of contact with English (Francophones in Ontario). This is the corpus in which we document innovations that may be attributable to transfer from English. We also consider data for Francophones who are not in a situation of contact with English (Francophones in Quebec City). Such data are crucial to establish that 
the 'innovations' in question are not developments that could arise due to internal factors. Finally, we draw on second language (L2) data produced by learners of French whose dominant language is English (French Immersion Students). The usefulness of these data lies in the fact that they provide additional evidence for the demonstration that the innovations are due to transfer from English. Needless to say, the use of these comparative corpora is not sufficient in itself to convincingly show that the innovations are transfer-induced. In addition, one must also produce convincing structural arguments for the causative role of transfer in the emergence of the innovations, a matter which we will address in the paper.

\section{The Ontario Corpus}

The corpus on which our analysis of contact-induced innovations is based was gathered within the Frenchspeaking minority population of Ontario, Canada (the Mougeon and Beniak corpus). The corpus was collected in the late 1970s via face-to-face interviews among 119 adolescent speakers who attended French-language high schools and who resided in four communities that represent different points along a continuum of contact with English, reflected by the relative proportion of Francophones to Anglophones at the local level. The four communities considered are as follows: a) Hawkesbury, where $85 \%$ of the residents are Francophones and, thus, where contact with English is weak; b) Cornwall, where $35 \%$ of the residents are Francophones and, thus, where contact with English is considerably more intense than in Hawkesbury; c) North Bay, where $17 \%$ of the residents are Francophones and, thus, where contact with English is even more intense; and finally d) Pembroke, where only $8 \%$ of the residents are Francophones and which thus represents the highest level of contact with English among these four communities.

This corpus also permits us to investigate the influence of contact with English at the individual level. The speakers from these four communities use French and English in their daily life at varying levels of frequency as measured by a global index of frequency of use of French in eleven communicative situations. In the corpus they have been regrouped into three categories (see Table 1): i) unrestricted speakers of French (their index value ranges from 100 to 80 , they are predominant users of French and rate themselves for the most part as French-dominant bilinguals); ii) semi-restricted speakers of French (their index value ranges from 79 to 45 , they experience a higher level of contact with English than the unrestricted speakers and they also tend to rate themselves as balanced bilinguals); iii) restricted speakers of French (their index value ranges from 44 to 05 and most of them rate themselves as dominant in English). It should also be pointed out that all of these adolescents were raised in a home where at least one of the parents was of French mother tongue (see Table 1) and that when they were interviewed they were all enrolled in a high school where they had been educated entirely in French. ${ }^{1}$

\section{Innovations in minority and majority languages}

Following Mougeon and Beniak (1991), in the present study we use the term 'innovation' to refer to developments found primarily or exclusively in the speech of the adolescents who exhibit the highest level of contact with English and restriction in the use of French or in the speech of the adolescents from the minority communities. Put differently, such developments are not features of the traditional norm spoken by the residents of the majority Francophone community of Hawkesbury and the adolescents who are unrestricted users of French. Obviously such developments can include phenomena that have either an inter-systemic or an intra-systemic origin or whose origin is ambiguous (see Mougeon, Bélanger and Canale, 1979; Mougeon and Beniak, 1991). Given that the Mougeon and Beniak corpus was gathered only among adolescents, the term 'innovation' should not be understood in the narrow diachronic sense (i.e. the developments that are characteristic of the adolescent restricted speakers may also be found in the speech of older restricted speakers; see Dubois and Noetzel in this issue, for several illustrations of this possibility in the Cajun French-speaking community).

Because restricted speakers exhibit high levels of contact with English and reduced usage of French, one can expect that their speech will include innovations that are attributable to various forms of inter-systemic transfer (e.g. borrowings, interference), or to intra-systemic processes (e.g. analogical regularization, reduction of elements inferable from the linguistic context or situation, universal tendencies) or to both processes. Although the present paper focuses on the first type of innovations, it is important not to lose sight of the second type (see notably Nadasdi, 2000, in press; Mougeon, 2004) and of the fact that some innovations are attributable to вотн inter-systemic and intra-systemic factors. In fact, these latter innovations underscore the necessity to demonstrate beyond any reasonable doubt that the innovations in question are indeed due only to inter-systemic transfer.

It is important at this point to clarify our conception of innovations in a language contact situation. As we have indicated above, high levels of restriction in the use of a minority language and contact with a majority language can bring about the emergence of innovations. Some of these innovations can be the result of conscious processes, while others can be the result of unconscious

1 Prior to attending a French language high school they had attended a French language elementary school. 
Table 1. Distribution of speakers in the Mougeon and Beniak corpus as a function of frequency of use of French in eleven informal situations.

\begin{tabular}{|c|c|c|c|c|c|c|c|}
\hline $\begin{array}{l}\text { Speaker } \\
\text { No }\end{array}$ & $\begin{array}{l}\text { Level of } \\
\text { restriction }\end{array}$ & $\begin{array}{l}\text { Speaker } \\
\text { No }\end{array}$ & $\begin{array}{l}\text { Level of } \\
\text { restriction }\end{array}$ & $\begin{array}{l}\text { Speaker } \\
\text { No }\end{array}$ & $\begin{array}{l}\text { Level of } \\
\text { restriction }\end{array}$ & $\begin{array}{l}\text { Speaker } \\
\text { No }\end{array}$ & $\begin{array}{l}\text { Level of } \\
\text { restriction }\end{array}$ \\
\hline H01 F/F & 100 & $\mathrm{P} 02 \mathrm{~F} / \mathrm{F}$ & 86 & P18 F/F & 64 & $\mathrm{P} 25 \mathrm{~F} / \mathrm{F}$ & 41 \\
\hline $\mathrm{H} 02 \mathrm{~F} / \mathrm{F}$ & 100 & P30 F/F & 86 & $\mathrm{~N} 24 \mathrm{~F} / \mathrm{F}$ & 61 & $\mathrm{C} 22 \mathrm{~F} / \mathrm{F}$ & 39 \\
\hline H03 F/F & 100 & $\mathrm{C} 35 \mathrm{~F} / \mathrm{F}$ & 82 & N17 F/F & 59 & $\mathrm{~N} 10 \mathrm{~F} / \mathrm{E}$ & 39 \\
\hline H04 F/F & 100 & N01 F/F & 82 & N16 F/F & 57 & P28 F/E & 39 \\
\hline H05 F/F & 100 & N33 F/E & 82 & N18 F/F & 57 & $\mathrm{C} 02 \mathrm{~F} / \mathrm{F}$ & 36 \\
\hline H06 F/F & 100 & $\mathrm{C} 21 \mathrm{~F} / \mathrm{F}$ & 80 & N09 F/F & 57 & $\mathrm{~N} 20 \mathrm{~F} / \mathrm{E}$ & 36 \\
\hline H09 F/F & 100 & H08 F/F & 78 & $\mathrm{C} 37 \mathrm{~F} / \mathrm{F}$ & 55 & N06 F/F & 34 \\
\hline $\mathrm{H} 11 \mathrm{~F} / \mathrm{F}$ & 100 & $\mathrm{C} 16 \mathrm{~F} / \mathrm{F}$ & 77 & N08 F/F & 55 & $\mathrm{C} 04 \mathrm{~F} / \mathrm{F}$ & 32 \\
\hline H12 F/F & 100 & $\mathrm{C} 20 \mathrm{~F} / \mathrm{F}$ & 77 & N34 F/F & 55 & P06 F/F & 32 \\
\hline H13 F/F & 100 & $\mathrm{~N} 19 \mathrm{~F} / \mathrm{F}$ & 77 & $\mathrm{P} 12 \mathrm{~F} / \mathrm{F}$ & 55 & N13 F/F & 30 \\
\hline $\mathrm{H} 14 \mathrm{~F} / \mathrm{F}$ & 100 & $\mathrm{~N} 21 \mathrm{~F} / \mathrm{F}$ & 77 & $\mathrm{P} 17 \mathrm{~F} / \mathrm{F}$ & 55 & $\mathrm{C} 24 \mathrm{~F} / \mathrm{E}$ & 27 \\
\hline $\mathrm{H} 15 \mathrm{~F} / \mathrm{F}$ & 100 & $\mathrm{~N} 30 \mathrm{~F} / \mathrm{F}$ & 77 & P31 F/F & 55 & $\mathrm{C} 07 \mathrm{~F} / \mathrm{E}$ & 25 \\
\hline $\mathrm{H} 17 \mathrm{~F} / \mathrm{F}$ & 100 & $\mathrm{C} 33 \mathrm{~F} / \mathrm{F}$ & 75 & P29 F/F & 53 & $\mathrm{C} 38 \mathrm{~F} / \mathrm{E}$ & 25 \\
\hline $\mathrm{H} 18 \mathrm{~F} / \mathrm{F}$ & 100 & $\mathrm{C} 12 \mathrm{~F} / \mathrm{F}$ & 75 & $\mathrm{C} 31 \mathrm{~F} / \mathrm{F}$ & 52 & $\mathrm{P} 23 \mathrm{~F} / \mathrm{F}$ & 25 \\
\hline H19 F/F & 100 & $\mathrm{~N} 11 \mathrm{~F} / \mathrm{F}$ & 75 & $\mathrm{P} 20 \mathrm{~F} / \mathrm{F}$ & 52 & P05 F/E & 23 \\
\hline $\mathrm{H} 20 \mathrm{~F} / \mathrm{F}$ & 100 & $\mathrm{~N} 36 \mathrm{~F} / \mathrm{F}$ & 75 & $\mathrm{C} 25 \mathrm{~F} / \mathrm{F}$ & 50 & P24 F/E & 22 \\
\hline $\mathrm{C} 23 \mathrm{~F} / \mathrm{F}$ & 98 & P09 F/F & 73 & P07 F/F & 50 & $\mathrm{~N} 29 \mathrm{~F} / \mathrm{E}$ & 20 \\
\hline $\mathrm{H} 07$ F/F & 97 & $\mathrm{C} 39 \mathrm{~F} / \mathrm{F}$ & 70 & $\mathrm{C} 18 \mathrm{~F} / \mathrm{F}$ & 48 & P14 F/F & 20 \\
\hline $\mathrm{C} 09 \mathrm{~F} / \mathrm{F}$ & 95 & $\mathrm{~N} 22 \mathrm{~F} / \mathrm{F}$ & 70 & $\mathrm{P} 16$ F/F & 48 & $\mathrm{P} 27 \mathrm{~F} / \mathrm{E}$ & 20 \\
\hline N07 F/F & 95 & $\mathrm{~N} 25 \mathrm{~F} / \mathrm{F}$ & 70 & $\mathrm{C} 40 \mathrm{~F} / \mathrm{E}$ & 45 & $\mathrm{C} 11 \mathrm{~F} / \mathrm{E}$ & 18 \\
\hline $\mathrm{C} 06 \mathrm{~F} / \mathrm{F}$ & 93 & $\mathrm{C} 03 \mathrm{~F} / \mathrm{E}$ & 68 & N12 F/E & 45 & P13 F/F & 18 \\
\hline H16 F/F & 91 & $\mathrm{C} 08 \mathrm{~F} / \mathrm{F}$ & 68 & $\mathrm{~N} 26 \mathrm{~F} / \mathrm{F}$ & 45 & $\mathrm{C} 28 \mathrm{~F} / \mathrm{E}$ & 14 \\
\hline $\mathrm{C} 10 \mathrm{~F} / \mathrm{F}$ & 91 & $\mathrm{C} 05 \mathrm{~F} / \mathrm{E}$ & 66 & N31 F/F & 45 & P01 F/E & 11 \\
\hline $\mathrm{C} 17 \mathrm{~F} / \mathrm{F}$ & 91 & $\mathrm{C} 13 \mathrm{~F} / \mathrm{F}$ & 66 & $\mathrm{P} 19 \mathrm{~F} / \mathrm{F}$ & 45 & P08 F/E & 9 \\
\hline $\mathrm{C} 26 \mathrm{~F} / \mathrm{F}$ & 91 & $\mathrm{C} 34 \mathrm{~F} / \mathrm{F}$ & 66 & $\mathrm{P} 22 \mathrm{~F} / \mathrm{F}$ & 45 & P10 F/E & 9 \\
\hline N03 F/F & 91 & $\mathrm{C} 36 \mathrm{~F} / \mathrm{E}$ & 66 & $\mathrm{~N} 28 \mathrm{~F} / \mathrm{F}$ & 44 & P34 F/E & 8 \\
\hline N35 F/F & 91 & N05 F/F & 66 & $\mathrm{C} 27 \mathrm{~F} / \mathrm{E}$ & 43 & N02 F/E & 6 \\
\hline $\mathrm{H} 10 \mathrm{~F} / \mathrm{F}$ & 89 & P35 F/F & 66 & $\mathrm{C} 19 \mathrm{~F} / \mathrm{E}$ & 41 & $\mathrm{C} 29 \mathrm{~F} / \mathrm{E}$ & 5 \\
\hline $\mathrm{C} 01 \mathrm{~F} / \mathrm{F}$ & 86 & N04 F/F & 64 & $\mathrm{C} 32 \mathrm{~F} / \mathrm{F}$ & 41 & P21 F/E & 5 \\
\hline $\mathrm{C} 30 \mathrm{~F} / \mathrm{F}$ & 86 & $\mathrm{P} 15 \mathrm{~F} / \mathrm{F}$ & 64 & $\mathrm{~N} 32 \mathrm{~F} / \mathrm{F}$ & 41 & & \\
\hline
\end{tabular}

$\mathrm{C}=$ Cornwall; $\mathrm{H}=$ Hawkesbury; $\mathrm{N}=$ North Bay; $\mathrm{P}=$ Pembroke; $\mathrm{F} / \mathrm{E}=$ mixed marriage; $\mathrm{F} / \mathrm{F}=$ marriage between two Francophones . Situations: i) adolescent $\leftrightarrow$ students in class; ii) adolescent $\leftrightarrow$ students in school corridors; iii) mother $>$ adolescent; iv) father $>$ adolescent; v) father $\leftrightarrow$ mother; vi) adolescent $>$ mother; vii) adolescent $>$ father; viii) adolescent $\leftrightarrow$ siblings at home; ix) adolescent $\leftrightarrow$ siblings out of home; $x$ ) adolescent $\leftrightarrow$ friends at home; xi) adolescent $\leftrightarrow$ friends out of home.

processes. The latter innovations are especially interesting because they open up the possibility that if a significant number of speakers in the community produce them, linguistic change occurs on a large scale (Mougeon and Beniak, 1991) ${ }^{2}$ and without the processes of inter-speaker transference that have been documented in monolingual

2 The example provided by Mougeon and Beniak (1991) of such widespread linguistic change is the replacement of the preposition $\grave{a}$ before words such as télévision, radio, etc. with the preposition sur, modeled on the English preposition on, which can be used in or majority speech communities (Labov, 1972; L. Milroy, 1987; J. Milroy, 1992). Obviously, this possibility does not preclude the occurrence of inter-speaker transference (i.e. innovations may spread to speakers of the minority language who do not experience language contact or restriction to a degree that is high enough for their spontaneous production of the innovations).

this context. This case of linguistic change will be discussed in more detail later in this paper. 


\section{The Quebec French corpora}

While the unrestricted speakers mentioned above and the speakers from Hawkesbury are very frequent or categorical users of French in the situations considered, they nonetheless experience some measure of contact with English by virtue of the fact that they reside in communities where they have varying opportunities to come into contact with Anglophones and hence be exposed to or use English. To examine the speech of adolescents who experience little or no contact with English, a corpus of French was gathered among 15 sameage speakers who live in Quebec City, a locality where Francophones constitute an overwhelming majority. This corpus was also gathered in the 1970s via taped interviews based on the same questions that were used with the Franco-Ontarian adolescents. The comparison of the speech of Franco-Ontarian adolescents with that of speakers of French from Quebec City is justified on both theoretical and methodological grounds since, on the one hand, the latter speakers provide us with a 'unilingual' benchmark that can be used to assess the possible effect of weak contact with English and, on the other hand, Ontario French can be looked upon as a transplanted variety of Quebec French. ${ }^{3}$ Given that our Quebec City spoken French corpus is based on a limited number of speakers, we have also examined the corpus of Quebec adult spoken French gathered in the 1970s by Beauchemin and Martel among Francophones residing in Sherbrooke and its suburbs. Their corpus is based on a sample of 148 speakers and it was also gathered in a locality where contact with English was very weak or nil.

\section{The L2 data}

The comparative L2 data upon which we will draw is made up of 41 adolescent French Immersion Students. The immersion programs in which the data were collected are housed in regular English-language high schools, where the great majority of the administrative, teaching, and maintenance staff, and also students, speak English rather than French. In other words, the classrooms where these students take their French-medium courses and the resource rooms attached to the French immersion programs are about the only settings in which they have the chance to use and be exposed to French. Outside this setting, English is the dominant language.

None of the 41 Immersion Students comes from a home where either parent speaks French. While many speak a language other than English at home, English does remain a dominant language for these students. While most of the

\footnotetext{
3 Ontario's Francophone community is essentially the result of several migratory waves emanating from Quebec at various points during Ontario's history of European settlement.
}

students have stayed in Francophone environments, only 14 of them have stayed with a Francophone family, for the most part in Quebec. The average length of stay for these 14 students is a relatively modest 16 days.

Concerning the students' use of French in their everyday life at school and outside the school, a questionnaire survey has revealed the following trends. The only situation in which the students report making significant use of French is in their in-class communications with their immersion teachers. When they communicate with their classmates within the confines of the classroom, they sometimes use French; however, outside the classroom their use of French is marginal. As for their use of French outside the school setting (e.g. with friends, neighbours, etc.), the students rarely or never use this language, a finding reflecting the scarcity of Francophones in the localities where they reside.

To sum up, the spoken French of the Immersion Students mentioned above provides a benchmark that allows us to assess the effect of a level of contact with English that is higher than that exhibited by Mougeon and Beniak's restricted adolescent speakers. Still, it is important to stress that these immersion speakers are advanced FSL learners.

With these three bodies of data in mind, let us now consider the methodological approach on which our analyses of contact-induced innovations are based (an earlier description of this approach can be found in Nadasdi, 2000).

\section{A four-step approach for the analysis of contact-induced innovations}

Before we summarize our methodological approach, we need to make it clear that there are two types of transferinduced innovations that can be the object of methodical scrutiny in order to demonstrate that they are indeed due to inter-systemic transfer: i) overt inter-systemic transfer, versus ii) covert inter-systemic transfer. To illustrate the concept of overt inter-systemic transfer, we can mention the use of French restrictive adverb juste "only" to the left of the verb (e.g. tu juste mets du sel dedans), a departure from the syntax of juste and of other French adverbs that can be attributed to transfer from the syntax of English restrictive adverb just "you just put salt in it". This case of overt interference was attested in the speech of restricted adolescent speakers of Ontario French and in that of Anglophone French Immersion Students by, respectively, Rehner and Mougeon (1997) and Mougeon and Rehner (2001). Overt transfer differs from covert transfer in that the former represents a qualitative development in the minority language. In the example discussed above, the qualitative change consists in a relaxing of the rule of French syntax that blocks insertion of an adverb between a subject clitic pronoun 
and the verb. In contrast, covert inter-systemic transfer consists only in a quantitative development, namely a marked increase in the frequency of a feature of the minority language at the expense of an alternative feature (or alternative features). Such an increase reflects the fact that the majority language (language B) possesses a feature semantically and morphologically similar to the rising feature of the minority language (language A). A case of covert transfer that was attested by Rehner and Mougeon (1997) is a marked rise in the frequency of restrictive adverb juste at the expense of alternative restrictive adverbs rien que, seulement and ne... que, all meaning "only" in the speech of the speakers of Ontario French who exhibit the highest levels of contact with English. According to these two authors such a rise can be ascribed to the fact that such speakers converge towards juste on account of its semantic and morphological similarity to English restrictive adverb just.

Both types of transfer discussed above are problematic in that they require a solid demonstration of the fact that they are indeed induced by language contact and that no competing alternative internal explanations can be invoked (see below). However, due to space limitations, the present study will be limited only to cases of overt transfer.

Let us now present the methodological steps that are necessary for the demonstration of transfer-induced change. The first two steps involve reasoning at the systemic level (as opposed to extra-systemic).

IN THE FIRST STEP, one must determine if the innovation attested in language $\mathrm{A}$ has an equivalent feature in language B. Equivalent features can include cognates or semantically equivalent elements. Such features constitute the first piece of evidence that the innovation under study may be the result of transfer from language B. Note that in this step it is important to consider not the standard variety of language $B$, but the one that is actually in contact with language A. Furthermore, the distribution of the innovation in question must be the same as what is found in the majority language (see Vinet, 1984).

IN THE SECOND STEP, one must consider whether or not the innovative feature can be attributed to internallymotivated processes (e.g. overgeneralization or other forms of analogical regularization) based on an analysis of both the feature in question and other potentially analogous features of language B. If such internal processes can be invoked as plausible explanations for the innovation in question, this will weaken the case for contact-induced change. Indeed, even if the innovation is found primarily or exclusively in the speech of speakers who exhibit the highest level of contact (see step four below), as restricted speakers of language $\mathrm{A}$, these speakers are also as we have pointed out likely to exhibit the strongest tendency to resort to processes such as overgeneralization or regularization.
IN THE THIRD STEP, one can consider other varieties of language $A$ to see if they include the feature in question or not. Two categories of varieties can be considered: a) those that could provide evidence militating against contact-based explanations of the innovation and b) those that could include evidence bolstering the case for contact-induced change. The first category includes: i) varieties of language $\mathrm{A}$ spoken in settings where there is little or no language contact (i.e. majority or unilingual speech communities - for example, Quebec French in our own research), including child speech, and ii) those varieties spoken in communities where language A comes into contact with a language other than B and which does not possess an equivalent feature to the innovation in question. Varieties that can lend support to the hypothesis of intersystemic transfer include: i) varieties of language $A$ also in contact with language $B$ but spoken in other communities (e.g. French spoken in the majority Anglophone provinces of Manitoba or Alberta or in the North-Eastern US) and ii) varieties of language $\mathrm{A}$ in contact with languages related to $\mathrm{B}$ or with dialects of $\mathrm{B}$ and that possess an equivalent feature to the innovation under study (e.g. Treffers-Daller (this volume) uses evidence provided by two Germanic dialects that French comes into contact with in the cities of Brussels and Strasbourg to support the hypothesis that a given innovation found in the local varieties of French is rooted in language contact). Ideally, the control varieties of language $A$ should be genetically related to ensure that the systems in which the innovations are found are similar and hence comparable. As far as French is concerned, Canada provides an interesting setting since it includes several genetically-related varieties that are spoken in communities exhibiting varying levels of language contact or no contact at all. Finally, one may also find relevant evidence in the interlanguage of L2 learners of language A. Here, again, two types of interlanguage can be considered. The first type consists of the interlanguage of L2 learners who speak language B as their first language or of learners who acquire languages A and B simultaneously (e.g. Pupier et al.'s 1982 corpus on the simultaneous acquisition of French and English by young children in Montreal). Such interlanguage data can provide additional evidence supporting contactbased explanations. The second type consists of the interlanguage of L2 learners of language A who speak a language other than B and THAT DOES NOT POSSESS AN EQUIVALENT FEATURE TO THE INNOVATION IN QUESTION. Such interlanguage is obviously a potential source of evidence militating against contact-based explanations.

IN THE FOURTH STEP, one must carefully examine the distribution of the innovation within the speech community where it has been documented as a function of factors such as degree of contact or bilingualism. A positive linear correlation with such factors will 
strengthen the case for contact. It should be pointed out, however, that while such a correlation is a necessary piece of evidence for the demonstration of contactinduced change, it is not sufficient on its own. Indeed it would be possible to find the same correlation in relation to an innovation due to internal processes of simplification since, as we have pointed out earlier, the higher the level of contact with language B the higher the level of restriction in the use of language A. Furthermore, as is clearly shown by Noetzl and Dubois in this volume, transfer-induced innovations can undergo processes of diffusion within minority speech communities and hence gradually lose their association with the restricted speakers of language A. Obviously when such a process of diffusion reaches completion (i.e. all the speakers within the minority speech community use the innovations in question), the evidence provided by steps one to three of our methodology becomes key to demonstrating that the innovation is rooted in contact.

To exemplify our four-step methodology, we will briefly discuss two innovations attested in the Mougeon and Beniak corpus of Ontario adolescent spoken French: i) one where the four steps yield evidence that leads one to look upon the innovation as due to inter-systemic transfer; and ii) one where the evidence leads one to look upon the innovation as due to intra-systemic factors.

To see how one can arrive at the conclusion that an innovative feature is likely due to inter-systemic contact, consider the use of the preposition sur "on" before words like radio "radio" and télévision "television" and TV and radio station names (cf. Mougeon and Beniak, 1991). An example of this innovation appears in (1), while the 'traditional' equivalent, use of the preposition $a$ in the same context, is illustrated in (2).

(1) c'est toute de la musique sur la radio $\mathrm{C} 3^{4}$ "it's nothing but music on the radio"

(2) il y a pas de programmes à la radio on va dire "there are no programs on the radio let's say"

With this innovation in mind, let us proceed through the four steps outlined above:

- SteP ONE: Is there an equivalent feature in language B? English uses the preposition on, the equivalent of sur in this context with the same meaning (e.g. on the television/TV, on the radio). As such, the question of contact-induced change can be raised.

- Step two: Can the innovation be looked upon as the outcome of a process of regularization?

4 Each example is followed by a code identifying the speaker's locality of residence $(\mathrm{C}=$ Cornwall, $\mathrm{H}=$ Hawkesbury, $\mathrm{N}=$ North Bay, $\mathrm{P}=$ Pembroke) and including an ID number assigned to each speaker in the corpus.
The replacement of the generic locative preposition $\grave{a}$ "at" by the specific preposition of location sur is not a case of regularization but rather one of complexification.

- SteP THREE: Is there evidence in genetically-related varieties of language A militating for or against contact-based explanations?

Examination of our control corpus of Quebec City spoken French (and of the 1970 Sankoff and Cedergren corpus of Montreal spoken French) ${ }^{5}$ revealed that the use of sur in such contexts is absent in Quebec French, the sister dialect of Ontario French that is not as heavily in contact with English. Mougeon and Beniak also did not find any study on the acquisition of French by young learners of Quebec French having attested the use of sur in the above-mentioned contexts. In contrast, there is considerable evidence in our corpus of spoken French gathered among Anglophone immersion high school students that these students use sur much more frequently than $a$ in the above-mentioned contexts (i.e. in more than $80 \%$ of occurrences).

- STEP FOUR: Is the distribution of the innovation linearly correlated with level of contact with language $\mathrm{B}$ ?

Examination of the distribution of sur in the Mougeon and Beniak Franco-Ontarian corpus reveals that there is such a correlation. Sur is found only in the French minority communities of Cornwall, North Bay, and Pembroke (it is absent in the majority community of Hawkesbury) and it is more frequent in Pembroke (the weakest minority community) than in Cornwall (the strongest minority community) and it is considerably more frequent in the speech of the semi-restricted and restricted speakers than in that of the unrestricted ones. In other words, it is used primarily by those Francophones who make frequent use of English.

- Conclusion: the innovation is likely attributable to contact with English, since evidence for this is provided in each of the four steps of our methodology.

Consider now an example that, after applying our fourstep methodology, can be looked upon as a bone fide intra-systemic innovation, in spite of the fact that it has a parallel in the majority language. The innovation consists in occasional post-verbal use of the object pronouns of French that are 'normally' used pre-verbally in declarative sentences (cf. Nadasdi, 2000). The innovation is illustrated in example (3) and the traditional usage in (4).

\footnotetext{
5 In this particular study, Daniel Valois checked the Sankoff and Cedergren corpus for Mougeon and Beniak (1991) to ascertain that sur + radio/télévision was nonexistent in Quebec French.
} 
(3) on rentre dans la maison pis elle dit à

nous autres «Parlez en français»

P31

"we go into the house and she says to us 'Speak French",

(4) elle nous pogne pis elle nous dit de parler français

"she catches us and she tells us to speak French"

The application of our methodology is as follows:

- SteP ONE: Is there an equivalent feature in language $\mathrm{B}$ ?

In English, all object pronouns appear after the verb. This raises the possibility that the emerging tendency to use object pronouns such as me, te, se, lui, nous, "me, you, it, him, her, us", etc. post-verbally has been triggered by contact with English.

- Step two: Can the innovation be looked upon as the outcome of a process of regularization?

Fronting of object pronouns is an exceptional feature of the morphosyntax of French (normal order is SVO). In all varieties of French, NP objects and many pronominal objects such as ça, celui/-là, tous, certains, aucuns "it, this/that one, all, some, none", etc. always appear post-verbally. Therefore, placing the exceptional preverbal object pronouns after the verb can be looked upon as a form of syntactic regularization.

- SteP THREE: Is there evidence in genetically-related varieties of language A militating for or against contact-based explanations?

Research on the use of clitic pronouns by adult speakers of Montreal French has brought to light the fact that at least two of the preverbal object pronouns of French (namely impersonal le/la and $y$ "him/her/it" and "here/there") tend to be used postverbally as ça "that" and là "there", respectively (see Thibault, 1983). In other words, there are signs in Quebec French that some of the preverbal pronouns are in competition with equivalent tonic forms used to the right of the verb. Fox (2004) has documented instances of post-verbal uses of the personal pronouns le and les "it/them" in the speech of restricted speakers of French in Woonsocket, Massachusetts (USA). ${ }^{6}$ Finally, post-verbal usage of tonic equivalents (e.g. moi, toi "me, you") of unstressed personal object pronouns (e.g. me, te "me, you") has been documented in the speech of L1 Francophone children (Grégoire, 1947, pp. 105, 106, e.g. il pette [frappe] moi, "he hits me"; je viens regarder toi lessiver "I'm coming to see you wash

6 Most of these speakers of French in this particular Franco-American community are either Quebec born or of Quebec ancestry. the laundry"). ${ }^{7}$ Turning to the interlanguage of FSL learners, it is noteworthy that if post-verbal usage of the preverbal object pronouns has been found in the speech of Anglophone learners of French (our Immersion French corpus includes many instances of such usage), such usage has also been found in the interlanguage of FSL learners from a variety of language backgrounds (see for instance Coupier (1983), who attested such usage in the interlanguage of FSL learners speaking Moroccan Arabic as a first language).

- STEP FOUR: Is the distribution of the innovation linearly correlated with level of contact with language $\mathrm{B}$ ?

The innovation is present only in the minority communities of Cornwall, North Bay, and Pembroke and only in the speech of the semi-restricted and restricted users of French (i.e. the speakers who are the most likely to regularize the irregular features of the morphosyntax of French). ${ }^{8}$

- Conclusion: While one cannot definitely reject the possibility that English may play a reinforcing role in the emergence of this innovation, the evidence discussed above strongly suggests that the root cause of the innovation in question is a process of regularization triggered by restricted usage of French.

\section{Analysis}

We will now consider a series of innovations found in the Mougeon and Beniak corpus of adolescent Ontario French and we will show how our four-step methodology can be used to demonstrate that such innovations constitute genuine cases of inter-systemic transfer. These innovations, as well as semantically equivalent variants, also found in the Mougeon and Beniak corpus, are illustrated below.

\section{Innovations}

(5) Inspector Clouseau il regardait pour un homme "Inspector Clouseau he was looking for a man"

(6) mais là je vas chercher pour de l'emploi $C 24$ "but you know I am going to look for a job"

7 We would have preferred to use data from a study of the acquisition of Ontario or Quebec French by young unilingual Francophone children, but none of the few studies we could locate focused on the syntax of object pronouns.

8 For instance, these same speakers have been found to exhibit a marked tendency to use default singular verb forms instead of verb forms bearing a plural mark (Mougeon and Beniak, 1991, 1995); for example, eux-autres ils prend [singular] pour les Canadiens vs euxautres ils prennent [plural] pour les Canadiens "them they support the Montreal Canadiens [hockey club]". 
Variant

(7) bon ben là il cherchait sa serviette "okay well you know he was looking for his briefcase"

Innovation

(8) et le gars m'a frappé j'étais très peur là "and the guy hit me I was really scared you know"

Variant

(9) il fallait sortir du bois et on avait très peur "we had to get out of the woods and we were really scared"

Innovation

(10) quand je jouais le hockey ici à Pembroke "when I played hockey here in Pembroke"

Variant

(11) non je joue au hockey à peu près tout "no I play hockey that's about it"

Innovations

(12) peut-être je prendrais un voyage avec ma famille "maybe I'd take a trip with my family"

(13) peut-être aller sur un petit voyage "maybe go on a short trip"

Variants

(14) quand qu'on a été faire un voyage "when we went on a trip"

(15) j'pense pas d'aller en voyage "I don't think I'm going to go on a trip"

(16) j'aimerais comme voyager à l'ouest "I would like like to go on a trip west"

Innovation

(17) ça dépend sur les parents "that depends on the parents"

Variants

(18) tout dépend de l'élève puis du professeur "everything depends on the student and the teacher"

(19) ça dépend quoi c'qu'ils jouent "it depends what they play"
The distribution of these forms in the Ontario French corpus is illustrated in Table 2, where results are given for each of the communities and for each level of French language use restriction.

We will now consider each of these examples in turn. In order to show why we have come to the conclusion that the innovative usages illustrated above are the result of contact with English, we will apply the four steps of our methodology to each case.

\section{Regarder pour and chercher pour}

The first innovation (example (5)) involves the use of the verb regarder "to look" followed by the preposition pour "for" and an object NP. This construction expresses the notion of "looking for" or "searching for" as illustrated in the English translations. The second innovation involves the use of the verb chercher "to search" followed by the preposition pour, also meaning "to look for". These two innovations alternate with a 'traditional' variant (illustrated in (7)), namely chercher followed by a direct object (i.e. used without pour). ${ }^{9}$ We will consider each innovation separately.

\section{Regarder pour $+\mathrm{NP}$}

- SteP ONE: As the translations of examples (5) and (6) indicate, English uses a construction that closely mirrors the innovation under study, namely look + for + NP.

- STEP TWO: In English, when the object of a verb can be looked upon as an expected result or outcome of the action expressed by the verb, one often uses the preposition for (the equivalent of pour) before the object. This pattern is illustrated by a large series of verbal constructions such as wait for + NP, ask for + NP, hope for + NP, try for + NP, strive for + NP, fish/hunt for + NP, etc. In contrast, in French the resultative relation holding between a verb and its object is, in most instances, an inherent semantic feature of the verb. Consequently the French equivalents of the above-mentioned English verbs are not followed by pour but by a direct object or infinitive clause introduced by the complementizing preposition de "to" (e.g. demander un service "ask for a favor", espérer une belle

9 The Franco-Ontarian adolescents also use a construction that is semantically related but not completely synonymous with chercher, namely essayer + de + trouver "try to find"; for example, Ils essayaient de trouver la terre "They were trying to find the earth". It was not included in the frequency calculation of the innovations and their variants because in contrast to chercher $+\mathrm{NP}$ and the two innovations under investigation, essayer de trouver expresses the more specific notion that the search involves effort and latency (i.e. the act of finding cannot occur immediately after the attempt at finding). 
Table 2. Distribution of innovations and their traditional counterparts across communities and speaker groups.

\begin{tabular}{|c|c|c|c|c|c|c|c|c|c|c|c|c|c|c|}
\hline \multirow[b]{3}{*}{ Variants } & \multicolumn{8}{|c|}{ Communities } & \multicolumn{6}{|c|}{ Speakers } \\
\hline & \multicolumn{2}{|c|}{ Hawkesbury } & \multicolumn{2}{|c|}{ Cornwall } & \multicolumn{2}{|c|}{ North Bay } & \multicolumn{2}{|c|}{ Pembroke } & \multicolumn{2}{|c|}{ Unrestricted } & \multicolumn{2}{|c|}{ Semi-restricted } & \multicolumn{2}{|c|}{ Restricted } \\
\hline & $\mathrm{N}$ & $\%$ & $\mathrm{~N}$ & $\%$ & $\mathrm{~N}$ & $\%$ & $\mathrm{~N}$ & $\%$ & $\mathrm{~N}$ & $\%$ & $\mathrm{~N}$ & $\%$ & $\mathrm{~N}$ & $\%$ \\
\hline Regarder pour* & 0 & 0 & 2 & 15 & 1 & 9 & 2 & 14 & 0 & 0 & 2 & 9 & 3 & 23 \\
\hline Chercher pour & 2 & 34 & 3 & 23 & 1 & 9 & 0 & 0 & 4 & 44 & 1 & 5 & 1 & 8 \\
\hline Chercher* & 4 & 66 & 5 & 38 & 5 & 45 & 7 & 50 & 4 & 44 & 12 & 54 & 5 & 30 \\
\hline$\hat{E}$ tre peur & 0 & 0 & 5 & 9 & 1 & 3 & 8 & 24 & 0 & 0 & 0 & 0 & 14 & 52 \\
\hline Avoir peur & 16 & 100 & 52 & 91 & 31 & 97 & 26 & 76 & 34 & 100 & 78 & 100 & 13 & 48 \\
\hline Jouer $+X$ & 0 & 0 & 11 & 36 & 3 & 27 & 17 & 45 & 3 & 11 & 11 & 39 & 15 & 41 \\
\hline Jouer à $+\mathrm{X}$ & 14 & 100 & 19 & 64 & 8 & 73 & 21 & 55 & 23 & 89 & 17 & 61 & 22 & 53 \\
\hline Prendre un voyage & 0 & - & 1 & 10 & 6 & 45 & 1 & 6 & 1 & 5 & 3 & 7 & 4 & 18 \\
\hline Avoir étélaller sur un voyage & 0 & - & 1 & 10 & 2 & 22 & 1 & 6 & 0 & 0 & 1 & 2 & 3 & 14 \\
\hline Faire un voyage & 2 & - & 7 & 70 & 3 & 27 & 1 & 6 & 7 & 35 & 4 & 9 & 2 & 9 \\
\hline Aller en voyage & 1 & - & 2 & 10 & 1 & 1 & 1 & 6 & 3 & 15 & 1 & 2 & 1 & 5 \\
\hline Voyager & 2 & - & 14 & & 25 & & 12 & 75 & 9 & 45 & 32 & 78 & 12 & 54 \\
\hline Dépendre + sur & 2 & 7 & 4 & 15 & 3 & 23 & 6 & 31 & 3 & 7 & 6 & 22 & 6 & 34 \\
\hline Dépendre +0 & 7 & 25 & 8 & 30 & 1 & 8 & 3 & 16 & 11 & 26 & 4 & 15 & 4 & 22 \\
\hline Dépendre + de & 19 & 68 & 15 & 55 & 9 & 69 & 10 & 53 & 28 & 67 & 17 & 63 & 8 & 44 \\
\hline Sur + rad./tv/station & 0 & 0 & 23 & 72 & 22 & 73 & 38 & 78 & 5 & 26 & 41 & 82 & 37 & 88 \\
\hline$\grave{\mathrm{A}}+\mathrm{rad} . / \mathrm{tv} /$ station & 16 & 100 & 5 & 28 & 8 & 27 & 11 & 22 & 14 & 74 & 9 & 18 & 5 & 12 \\
\hline
\end{tabular}

* Word in italics = innovation; Word in Roman = variant; $\mathrm{X}=$ NP referring to a game or sport.

récolte "to hope for a good crop", essayer d'obtenir de meilleurs résultats "strive for better results"). ${ }^{10}$ This means, then, that the construction regarder pour + NP cannot be looked upon as the outcome of a process of morphosyntactic regularization.

- STEP THREE: Examination of our corpus of Quebec City adolescent spoken French and of the Sherbrooke corpus of adult spoken French revealed an absence of the construction regarder + pour + NP (meaning "to look for"). Also, in the child language studies that we have examined we found no attestation of this construction. There is, however, one occurrence of regarder + pour in our corpus of Immersion spoken French, which alternates with two occurrences of chercher + pour and a dozen occurrences of chercher + NP.

10 It is true that in casual French the $\mathrm{Vb}+$ pour + NP pattern can, with certain verbs, be looked upon as the outcome of a rule that deletes a resultative infinitive complement (e.g. le plombier est venu pour le robinet ["the plumber came for the faucet"] for le plombier est venu pour [réparer] le robinet ["the plumber came (to fix) the faucet"]). However, it would not be possible to argue that regarder pour + NP (or chercher pour + NP, for that matter) is the outcome of such deletion, since we know of no variety of French where the concept of "searching for" is expressed via an explicit structure such as regarder pour trouver $+\mathrm{NP} ; *$ Il a regardé pour trouver un emploi ["he looked to find a job"].
- STEP FOUR: Table 2 reveals that regarder pour is used most frequently in the speech of the adolescents from Pembroke (22\%) and never in the strong Francophone majority community of Hawkesbury. Note also that this form is found most often in the speech of restricted speakers (34\%) and never in that of the unrestricted ones.

- CONCLUSION:The evidence reviewed in the four steps of our methodology provides cumulative support for the hypothesis that regarder pour + NP is a contactinduced innovation.

\section{Chercher pour}

- Step OnE: As we pointed out above, English uses the preposition pour after verbs such as look and search to express the concept of "searching". 11

- Step two: For the reasons we have outlined in relation to regarder pour $+\mathrm{NP}$, one cannot link chercher + pour $+\mathrm{NP}$ to a process of morphosyntactic regularization.

- STEP THREE: Chercher pour does not occur in our corpus of Quebec French, nor does it occur in the Sherbrooke adult spoken French corpus or in

11 The English verb to search is descended from the Old French verb cerchier. 
the 1971 and 1984 corpora of Montreal spoken French. ${ }^{12}$ We have not found any attestation of this construction in French L1 acquisition research. On the other hand, there are, as we pointed out, two instances of chercher + pour in our French immersion corpus.

- Step four: As is shown in Table 2, the expected correlation between degree of language contact at the community or speaker level and the frequency of use of the chercher + pour is the reverse of the expected association: the higher the level of contact with English, the less frequent the use of the innovation.

One possible explanation for this exception is that while this particular construction involves the insertion of the preposition pour, it does not involve as much of a departure from the morphosyntax of French as does regarder + pour. The latter not only entails the insertion of pour, but also the substitution of regarder for chercher. Put differently, chercher pour is a more subtle manifestation of the influence of English than regarder pour and hence it is more likely to enter into the speech of adolescents who experience lower levels of contact than is regarder pour. We still need to explain why the restricted speakers use regarder pour more frequently than chercher pour. One possible explanation for this finding is that for these English-dominant bilinguals regarder pour is their borrowing of choice on account of the fact that it more closely matches the most common way of expressing the notion of "searching" in English, namely look for. Put differently, we would like to argue here that speakers who experience the highest level of contact show a preferential use for regarder pour at the expense of chercher pour (either via convergence or by producing this structure spontaneously in discourse).

- Conclusion: On the basis of the evidence adduced by our methodology, it is not unreasonable to suggest that the innovation chercher pour + NP is the result of language contact since the evidence yielded by the first three steps supports this view. However, it should be borne in mind that this particular innovation does not entail as much of a departure from the rules of French morphosyntax as does regarder pour, a fact that is consistent with the presence of this innovation in the spoken French of all speaker groups in the Mougeon and Beniak corpus. The absence of chercher + pour in Quebec French, however, underscores the fact that some

12 We are grateful to Hélène Blondeau for verifying this. We decided to take the extra step of checking two additional corpora of Quebec French for the two reasons discussed in Step Four. measure of contact with English is a necessary condition for the emergence of this innovation.

\section{Etre peur}

This particular innovation involves the use of the copula (être "to be" in French) with the 'Article-less Substantive' peur "fear" to express the notion of "being afraid" (see example (8)). This innovation alternates with the traditional variant which expresses this same notion with avoir "to have" also followed by the "Article-less Substantive' peur (see example (9)).

- STEP ONE: In English, one also expresses the notion of "being afraid" with the copula be, but the latter is followed by a past participle conveying the notion of "fear" (e.g. afraid, scared) and not by a noun (see the translations of examples (8) and (9)). In other words, there is only a partial match between the English equivalent and the innovation under study.

- SteP two: To express a state experienced by the subject, French uses either être followed by a past participle, an adjective or some equivalent attributive construction (e.g. je suis fatigué "I'm tired"; il est malade "he is sick") or avoir "have" followed by an 'Article-less Noun' that denotes the state (e.g. nous avons soif [we have thirst] "we are thirsty"). Of these two options, the former may be considered as unmarked, in that there are more states that cannot be expressed by avoir + an 'Articleless Noun' (e.g. fatigué and malade mentioned above) than states that are expressed with the avoir + noun construction. Having said this, one must bear in mind that the states that are expressed by the avoir + noun constructions refer to very basic notions likely to occur frequently in discourse (e.g. avoir faim, soif, froid, chaud, peur, mal, etc. "to be hungry, thirsty, cold, hot, afraid, to hurt"). Therefore it would be difficult to argue that the stative avoir + noun construction is a complex aspect of the morphosyntax of French and as such is a prime candidate for regularization. Furthermore, even if one were to look upon être + peur as the outcome of morphosyntactic regularization, one would have to account for the fact that in this construction the copula is followed by peur, an 'Article-less Noun', and not by an adjective. One way of accounting for this surprising usage would be to argue that peur has been reanalyzed as an adjective. The fact that we found three instances of the construction c'est peur ["it is fright"] used instead of the traditional variants c'est épeurant/effrayant "it is scary" lends support to this hypothesis. However, this, in turn, raises the issue of the INTERNAL factors that may lead speakers of French to reanalyze peur as an 
adjective. In this particular case very few internal factors (if any) come to mind. In sum, the case for intra-systemic regularization does not rest on very solid ground.

- SteP THREE: Etre peur was not found in our control corpus of Quebec City adolescent spoken French nor did we find it in the Beauchemin and Martel Sherbrooke corpus. Furthermore, we have not found documented cases of young Francophones producing this form during the acquisition process. In fact, in Grégoire's study of the acquisition of French by two young L1 Francophone children, one can find evidence that stative avoir constructions are acquired as early as age 2 (e.g. avoir mal "to have a pain; to hurt", avoir froid "to be cold" and avoir faim "to be hungry"). In contrast, in our corpus of adolescent immersion French, we found 27 instances of être peur (e.g. je suis peur que quelque chose va se passer "I'm afraid that something is going to happen") alternating with 33 occurrences of avoir peur and we also found seven occurrences of c'est peur and one of devenir peur ["to become fright"] meaning "to become scared"! Finally, Fox (2004), in a study of the variety of French spoken in Woonsocket, MA, and Jones (this issue), in a study centered on transfer from English in Jersey Norman French have also attested instances of the substitution of etre for stative avoir (aver in Jersey Norman French). Both varieties are very much threatened by English, and in Fox's study the substitution of etre for avoir is confined to the restricted speakers of French.

- Step fOUR: As is shown in Table 2 etre peur is found mostly in the minority community of Pembroke (never in Hawkesbury) and exclusively in the speech of restricted speakers who use this form $52 \%$ of the time.

- Conclusion: While there are some internal factors that may have favored the rise of this innovation, overall the evidence yielded by our methodology leads us to conclude that contact with English is a necessary condition for such a rise.

\section{Jouer + NP}

The innovation focused upon in this section consists in the use of the verb jouer "to play" followed by a direct object NP referring to a game or a sport (see example (10)). This innovation alternates with the use of the same verb followed by an indirect object introduced by the preposition $\grave{a}$ (see example (11)), the traditional variant.

- STEP ONE: The innovation under study has an equivalent in English, since in this language the 'natural' complements of the verb play (nouns referring to a game or a sport) are used as direct objects (see the translations of examples (10) and (11)).

- SteP TwO: In French, most verbs that are followed by an indirect object NP introduced by $a$ have a dative or directional meaning - for example, penser à "think of/about", parler/dire/raconter à "speak/say/recount to", apporter à "bring to", rêver à "dream about", pardonner $\grave{a}$ "forgive to". Thus, the use of the preposition $a$ with the verb jouer, which does not entail a directional or dative meaning, is exceptional. While this fact lends support to the idea that the innovation in question may be rooted in a process of regularization, it should be pointed out that the exceptional usage of the preposition à with jouer is not an insurmountable difficulty of the French language, especially if one takes into account the high frequency of the verb jouer.

- STEP THREE: In our control corpus of Quebec City adolescent spoken French and in the Sherbrooke corpus, jouer is always used with an indirect object introduced by the preposition $\dot{a}$. In the studies on the acquisition of French by young L1 speakers available to us, we have not found attestations of jouer used with a direct object. This lends support to the idea that jouer $+\grave{a}+\mathrm{NP}$ is not an overly difficult aspect of French morphosyntax. It may also reflect the fact that children often engage in a variety of games and hence do not lack opportunities to acquire the verbal construction used to refer to such engagement. In contrast, in our French Immersion corpus we found $95 \%$ of occurrences were jouer $+\mathrm{NP}$ and $5 \%$ of occurrences were jouer $+\grave{a}+$ NP. Such massive usage of jouer + NP on the part of the Immersion Students further weakens the intrasystemic regularization hypothesis since these same students have been found to use features of French morphosyntax that are more complex than the jouer $+\grave{a}+$ NP construction at levels of frequency comparable to that of L1 speakers of French (e.g. the inflected future, see Nadasdi, Mougeon and Rehner, 2003).

- STEP FOUR: The Franco-Ontarian community data presented in Table 2 reveal that jouer $+\mathrm{NP}$ is not found in the speech of individuals residing in the majority community of Hawkesbury. It is found in the minority communities and is most frequently used in Pembroke where one finds the fewest Francophones. Unrestricted speakers rarely use jouer + NP (11\%), whereas it is used with nonnegligible frequency in the speech of semi-restricted (39\%) and restricted (41\%) speakers.

- CONCLUSION: The evidence adduced by the four steps of our methodology leads us to conclude that the existence of jouer $+\mathrm{NP}$ is likely attributable to contact with English. 


\section{Prendre un voyage/aller sur un voyage}

This particular section is focused on two synonymous innovations: i) use of the verb prendre + un + voyage and ii) use of aller + sur $+u n+$ voyage (both meaning "to take a trip" or "to go on a trip") which alternate with three traditional variants: i) faire $+u n+$ voyage ["to make a trip"], ii) aller + en + voyage ["to go in trip"] or iii) voyager "to travel" (see examples (12)-(16)). ${ }^{13}$ Concerning this latter variant, it should be pointed out that in the Mougeon and Beniak corpus it was often used in answer to the question: Qu'est-ce que tu ferais si tu gagnais le gros lot à Wintario? "What would you do if you were to win the Wintario jackpot?". We assumed that answers such as $j$ 'aimerais voyager, je voyagerais or simply voyager meant "I would (like to) go on a trip" rather than a more generic answer "I would like to travel". As a result we may have overestimated the number of uses of the verb voyager conveying the specific meaning of "to go on a trip".

- STEP ONE: In English the concept of "going on a trip" can be expressed with the verb go (the equivalent of the French verb aller) followed by a complement such as trip, journey, excursion, expedition, tour, etc. or with the verb take (the equivalent of the verb prendre) followed primarily by the complement trip (the equivalent of the French noun voyage). In other words, the two innovations under study have exact equivalents in English.

- Step two: It is not possible to look upon the two innovations under study as the result of intrasystemic regularization for several reasons. The verb prendre in the innovation prendre un voyage is more specific than the polysemous and frequent verb faire in the traditional variant faire un voyage. Likewise, the preposition sur used in the innovation aller sur un voyage is more specific than the preposition en in the traditional variant aller en voyage.

- SteP THREE: We have not found any instances of aller sur un voyage or prendre un voyage in our Quebec City spoken French corpus, nor in the Sherbrooke spoken French corpus. In both corpora one finds the traditional variants faire un voyage or aller/partir en voyage. Likewise, aller sur un voyage and prendre un voyage are unattested in the studies on the acquisition of French as a first language that we consulted. In the French Immersion corpus, voyager is by far the dominant form, perhaps because it is the most simple of all the options. There is also one instance of prendre un voyage in that corpus.

13 It is also possible to use the expression partir en voyage. We found several occurrences of this latter construction in our Quebec City spoken French corpus, but there were none in the Mougeon and Beniak corpus.
- SteP fOuR: As is shown in Table 2, prendre un voyage and aller sur un voyage are unattested in the speech of the Hawkesbury adolescents and in that of the unrestricted speakers. We do, however, find this expression occasionally in the minority communities and in the speech of the semi-restricted and restricted speakers of French.

- Conclusion: On the basis of the evidence provided by the four steps of our methodology, we can conclude that the presence of prendre un voyage and aller sur un voyage in the Mougeon and Beniak corpus is likely attributable to contact with English.

\section{Dépendre sur}

The last innovation to be addressed in the present study consists of the use of the verb dépendre "to depend" with the preposition sur "on" followed by an object NP (example (17)). This innovation alternates with two traditional variants, namely the use of dépendre with the preposition de "of" and an object NP and the use of dépendre followed by a direct object (examples (18) and (19)). As is shown in Table 2, the latter variant is less frequent than the former one. Use of the verb dépendre without a preposition underscores the fact that in this particular context this preposition does not carry much semantic value. ${ }^{14}$

- SteP ONE: As the translation of example (18) indicates, English uses the preposition on (the equivalent of the preposition sur) before the complement of the verb depend (the equivalent of dépendre). Thus the innovation under study has an exact equivalent in English.

- Step two: It is not possible to argue that use of sur after dépendre is the result of an intra-systemic process of regularization for at least two reasons. There is no analogous construction in French where a verb similar in meaning to the verb dépendre is followed by the preposition sur. ${ }^{15}$ Furthermore, there is no reason for suggesting that the use of the preposition sur is more regular or less complex that the use of $d e$, and in fact one might reasonably argue that the polysemous preposition de is more unmarked than the specific preposition sur.

14 In casual speech it is also possible to delete in certain contexts the preposition on/upon in English after to depend.

15 There are two meanings associated with the verb dépendre: i) the specific meaning of "to rely upon" and the more abstract meaning of "referring to a circumstance or action upon which an action is contingent". Although the more specific meaning of "rely upon" can also be expressed with the verb s'appuyer sur "to lean on" it is unlikely that such a specific construction could be an analogical source for the innovation dépendre sur. 
Table 3. Evidence for or against innovations being due to language contact.

\begin{tabular}{|c|c|c|c|c|}
\hline Innovations & Step One & Step Two & Step Three & Step Four \\
\hline sur la télé/radio & yes & yes & yes & yes \\
\hline regarder pour & yes & yes & yes & yes \\
\hline être peur & yes & yes & yes & yes \\
\hline jouer + NP & yes & yes & yes & yes \\
\hline prendre un voyage/aller sur un voyage & yes & yes & yes & yes \\
\hline dépender sur & yes & yes & yes & yes \\
\hline chercher pour & yes & yes & yes & no \\
\hline post-posed personal object pronouns & yes & no & no & yes \\
\hline
\end{tabular}

- SteP THREE: Dépendre sur is not attested in our corpus of Quebec City adolescent spoken French and in the corpus of Sherbrooke French. In both corpora one finds only instances of dépendre de or dépendre without a preposition. We did not find attestations of dépendre sur in the studies of child speech that we consulted. In contrast, we found four instances of dépendre sur in our corpus of Immersion French speech alternating with seven instances of dépendre $d e$, one occurrence of dépendre $+\grave{a}$ "at" and 13 instances of dépendre used without a preposition.

- STEP FOUR: There is a linear correlation between frequency of dépendre sur and concentration of Francophones at the community level (see Table 2). This structure is rare in Hawkesbury (7\%) and fairly frequent in Pembroke (31\%). A similar correlation exists with language use restriction: the unrestricted speakers use dépendre sur $7 \%$ of the time, the semi-restricted speakers do so $22 \%$ of the time and the restricted speakers use it in $34 \%$ of occurrences. As in the case of chercher pour, the fact that we found instances of dépendre sur in the speech of the Hawkesbury adolescents and in that of the unrestricted speakers suggests that this latter innovation is not a major departure from the traditional norm. However, the absence of dépendre sur in the Quebec French corpora suggests that some measure of contact with English is required for such an innovation to emerge.

- Conclusion: The four steps of our methodology strongly suggest that while dépendre sur is the result of contact with English, it is not a major departure from the traditional norm.

\section{Discussion}

Let us now review how our four-step methodology has allowed us to adduce evidence in favor of or against the thesis that the innovations we have considered are, indeed, rooted in contact with English. This is indicated respectively by "yes" or "no" in each of the cells under Steps One-Four in Table 3.

As mentioned, the first necessary step in hypothesizing that an innovation is the result of contact with English is to identify a clear parallel in that language. As is shown in Table 3, in all the innovations under investigation one finds an equivalent usage that closely mirrors the meaning and morphosyntax of the innovations.

Concerning the second step, as is illustrated in Table 3, we have shown that for all but one of the innovations (the post-posing of tonic object personal pronouns - e.g. moi, toi "me, you"), the case for an intra-systemic cause is either not very strong or baseless. In other words, with the exception of the post-posed personal object pronouns none of the innovations can be easily analyzed as a case of morphosyntactic regularization or some other form of simplification reflecting the markedness or complexity of the traditional variants.

In relation to the third step, consultation of several corpora of Quebec French revealed that they do not include any occurrence of the innovations listed in Table 3 and, conversely, that they include only instances of the traditional variants used by the Franco-Ontarian adolescents. This finding lends considerable additional support to the hypothesis that the innovations under study are rooted in contact with English, since Quebec French is genetically related to Ontario French and experiences only weak or no contact with English. The fact that we did not find attestations of the innovations in question in the studies on the acquisition of French as a first language available to us also lends additional support to the above-mentioned hypothesis. It should be pointed out, however, that most of the studies that we consulted are based on corpora of first language child speech not gathered in Ontario or Quebec and hence the evidence they provide is not as compelling as that provided by the corpora of adult Quebec French. Finally, our corpus of French gathered among adolescents enrolled in French Immersion programs as well as a sub-corpus of spoken French gathered by Fox among restricted speakers in Woonsocket, MA, provide attestations of 
Table 4. Implicational distribution of innovations across communities and speaker groups.

\begin{tabular}{|c|c|c|c|c|c|c|c|c|c|c|c|c|c|c|}
\hline \multirow[b]{3}{*}{ Variants } & \multicolumn{8}{|c|}{ Communities } & \multicolumn{6}{|c|}{ Speakers } \\
\hline & \multicolumn{2}{|c|}{ Hawkesbury } & \multicolumn{2}{|c|}{ Cornwall } & \multicolumn{2}{|c|}{ North Bay } & \multicolumn{2}{|c|}{ Pembroke } & \multicolumn{2}{|c|}{ Unrestricted } & \multicolumn{2}{|c|}{ Semi-Restricted } & \multicolumn{2}{|c|}{ Restricted } \\
\hline & $\mathrm{N}$ & $\%$ & $\mathrm{~N}$ & $\%$ & $\mathrm{~N}$ & $\%$ & $\mathrm{~N}$ & $\%$ & $\mathrm{~N}$ & $\%$ & $\mathrm{~N}$ & $\%$ & $\mathrm{~N}$ & $\%$ \\
\hline Etre peur & 0 & 0 & 5 & 9 & 1 & 3 & 8 & 24 & 0 & 0 & 0 & 0 & 14 & 52 \\
\hline Regarder pour & 0 & 0 & 2 & 15 & 1 & 9 & 2 & 14 & 0 & 0 & 2 & 9 & 3 & 23 \\
\hline Avoir été/ aller sur un voyage & 0 & 0 & 1 & 10 & 2 & 22 & 1 & 6 & 0 & 0 & 1 & 2 & 3 & 14 \\
\hline Prendre un voyage & 0 & 0 & 1 & 10 & 6 & 45 & 1 & 7 & 1 & 5 & 3 & 8 & 4 & 21 \\
\hline Jouer $+X$ & 0 & 0 & 11 & 36 & 3 & 27 & 17 & 45 & 3 & 11 & 11 & 39 & 15 & 41 \\
\hline Sur + radio/tv & 0 & 0 & 23 & 72 & 22 & 73 & 38 & 78 & 5 & 26 & 41 & 82 & 37 & 88 \\
\hline Dépendre + sur & 2 & 7 & 4 & 15 & 3 & 23 & 6 & 31 & 3 & 7 & 6 & 22 & 6 & 34 \\
\hline Chercher pour & 2 & 34 & 3 & 23 & 1 & 9 & 0 & 0 & 4 & 44 & 1 & 5 & 1 & 8 \\
\hline
\end{tabular}

$\mathrm{X}=\mathrm{NP}$ referring to a game or sport.

all the innovations under study. This, too, reinforces the above-mentioned hypothesis since both categories of speakers of French exhibit high levels of contact with English. The only exception revealed by Step Three of our methodology is the post-posing of tonic forms of the personal object pronouns le, les, lui and leur "it/him, them, to him and to them", which is attested in studies on the acquisition of French as a first language and in studies of the acquisition of French as a second language by learners who speak a language that does not feature post-posing of object personal pronouns.

As is shown in Table 3, in all but one of the innovations under study (chercher pour) the evidence provided by Step Four of our methodology is consistent with the thesis of an intersystemic origin (i.e. the innovations are more frequent in the speech of the restricted speakers than in that of the semi-restricted speakers and a fortiori in that of the unrestricted speakers). Similarly, the innovations are more frequent in the minority communities (especially in the weak minority community of Pembroke) than in the strong majority community of Hawkesbury. While these findings constitute additional evidence supporting the inter-systemic origin hypothesis, this evidence is not as strong as that provided by Steps One-Three, since we would expect to find the very same correlations with level of restriction in the use of French if the innovations had an origin in a process of regularization or some other form of simplification. This is illustrated by the last row of Table 3, where Step Four reflects the fact that postposing of the tonic of the object personal pronouns was found to correlate with level of restriction and community of residence in the same way as the contact-induced innovations under study here (see Nadasdi, 2000).

Still, what we have just said regarding the evidence provided by Step Four does not mean that this evidence is without heuristic value. Such value is illustrated in Table 4, which provides an implicational display of the data on the frequency of the innovations under study according to level of restriction and community of residence. In this table, the communities and speaker groups in which the innovations were attested are shaded in gray.

As is shown in Table 4, the innovation which has the narrowest distribution across communities and speaker groups is etre peur. This innovation is found only in the minority communities and in the French of the restricted speakers. It is also noteworthy that the community in which this innovation's frequency of occurrence rises above $10 \%$ is Pembroke (the weakest of the three minority communities). That this innovation represents a major departure from the rules of traditional Ontario French morphosyntax (involving both the replacement of stative avoir by être and a re-analysis of the substantive peur as an adjective) is a likely explanation of the fact that it is only found in the French of the speakers who experience the highest levels of contact with English (i.e. the restricted speakers).

Further down the implicational scale, one finds two innovations that are attested in the minority communities and in the French of the semi-restricted and restricted speakers, namely aller/avoir été sur un voyage and regarder pour. That the distribution of these two innovations is not quite as narrow as that of etre peur may reflect the fact that although these two innovations are significant departures from traditional Ontario French morphosyntax, they are not quite as drastic as the departure represented by être peur. Specifically, unlike etre peur, the construction regarder pour $+\mathrm{NP}$ is not syntactically deviant. Where this latter construction departs from traditional Ontario French is in the meaning of the verb regarder which is more abstract than the meaning of regarder in traditional Ontario French, where this verb can only refer to the concrete action of "seeing" or "watching". Likewise, innovations aller/avoir été sur un voyage differ from the traditional variant aller en 
voyage mostly in relation to the fact that the specific preposition sur replaces the 'colorless' preposition en.

Still further down the implicational scale, one finds three innovations whose distribution is even less narrow that that of the innovations we have just discussed. They are not attested in Hawkesbury but they are present in the French of all three speaker groups. These innovations are prendre un voyage, jouer $+\mathrm{NP}$ and sur + radio/télévision. Once again, it is possible to account for this finding by arguing that the innovations in question represent departures from the traditional norm of Ontario French that are less pronounced than those entailed by the innovations discussed above. Specifically prendre un voyage involves only the replacement of the generic verb faire by prendre, a verb which can also take a generic meaning in several contexts. ${ }^{16}$ As for the innovation jouer $+\mathrm{NP}$, it involves the removal of the preposition $\grave{a}$ which in this particular context is semantically weak (if not void) and does not express its traditional dative or locative meaning. Finally, while the use of the specific preposition sur before the substantives radio and télévision and station names instead of the generic locative preposition $\grave{a}$ does represent a departure from the traditional norm, it is noteworthy that in non-Canadian varieties of French one finds signs that sur is in the process of acquiring a more generic locative meaning (cf. for instance, the use of sur instead of $\grave{a}$ in Hexagonal French in expressions like travailler sur Paris "to work in Paris", aller sur Lyon "to go to Lyons", and more to the point, in this same variety of French $\grave{a}$ was replaced by sur, in the late $1970 \mathrm{~s}$, before radio and television station names for example, à> sur Arte "on Arte", à > sur Europe No 1 "on Europe No 1"; see Mougeon and Beniak, 1991).

Further down the implicational scale one finds an innovation (dépendre sur) that is distributed in all four communities and in the French of all three speaker groups. It is noteworthy, however, that the frequency of this innovation is linearly correlated with level of restriction in the use of French and community of residence: the higher the level of restriction in the use of French, the higher the frequency of dépendre sur; and the lower the level of Francophone concentration at the local level, the higher the frequency of this innovation. As we have pointed out in the preceding section, in the traditional variant of this innovation (dépendre de $+\mathrm{NP}$ ) the preposition carries little or no semantic value and hence can undergo deletion, as in the other traditional variant (dépendre $+\mathrm{NP}$ ). Further, it may be argued that replacement of the preposition de by the preposition

16 Consider, for instance, constructions such as prendre la fuite "to escape", prendre du retard "to fall behind schedule", prendre peur "to become scared", and prendre de l'âge "to become old", where the basic meaning of prendre "to take" is lost. sur expresses explicitly the notion of "dependence" or "reliance" contained in the meaning of the verb dépendre. Thus, while the emergence of dépendre sur is triggered by contact with English (as indicated by the linear correlation mentioned above), it represents only a minor departure from the traditional norm and hence is distributed across all communities and speaker groups.

Finally, at the bottom of Table 4 one finds yet another innovation that is found across all four communities and speaker groups, namely the construction chercher pour. However, as indicated by the percentages of frequency found for this innovation, the correlation between the degree of language contact at the community or speaker level is the reverse of what was found in relation to dependre sur. As we have pointed out in the preceding section, this surprising finding is not an indication that chercher pour is not rooted in contact with English. Rather it reflects the fact that chercher pour is in competition with another contact-induced innovation, namely regarder pour, which closely resembles the English verbal constriction to look for and which as such is favored by the speakers who exhibit the highest level of contact with English. Having said this, that chercher pour is found in all four Francophone communities and all three speaker groups does reflect the fact that this innovation represents only a minor departure from the traditional norm.

In sum, our examination of the patterns of diffusion of innovations due to contact with English in Ontario French has shown that the innovations form an implicational scale which reflects the degree to which they depart from the rules of the morphosyntax of traditional Ontario French. At one end of the scale, one finds innovations that represent major departures from the rules of traditional Ontario French and whose distribution is restricted to the French of those speakers who experience the highest levels of contact with English. At the other end of the scale, one finds innovations that constitute only minor departures from the rules of traditional Ontario French and that are found across all localities and speaker groups. This finding suggests that there are thresholds of contact with English below which or above which innovations that deviate more or less from the traditional norm will or will not emerge. ${ }^{17}$ This does not mean that within specific speech communities contact-induced innovations cannot spread beyond the speech of the 'innovators'. In fact, in a minority speech community such as Pembroke, where the unrestricted adolescents are outnumbered by the semirestricted and restricted ones, such inter-speaker diffusion is a distinct possibility. If our corpus had included significantly more tokens of the innovations under study,

17 Our implicational scale is similar to that brought to light in Dubois and Noetzel's study of innovations in Cajun French (this issue), except that their scale captures both synchronic and diachronic inter-speaker variation. 
we could have examined this issue by calculating rates of frequency of a given innovation as a function of level of restriction for each of the three minority communities. Consequently the verification of this hypothesis will have to await further research. That said, the systemic and extra-systemic conditions that bring about the emergence of a contact-induced innovation and those that may subsequently favor its diffusion across speaker groups are two separable issues and the primary purpose of our paper has been to focus on the former issue rather than on the latter. $^{18}$

\section{Conclusion}

Our study has shown that by using the four-step methodology discussed above, it is possible to establish with reasonable confidence that certain innovations attested in a minority language are rooted in contact with a majority language. Thus, we believe that our study provides a useful tool to linguists who choose to focus on inter-systemic transfer either for the purpose of assessing the effect of language contact on language variation and change or of carrying out socially-sensitive descriptive studies of the distinctive features of minority languages.

In applying our methodology to an analysis of the eight innovations shown to be due to contact with English, we have found that the emergence of such innovations is conditioned by two key related factors: i) the intensity of contact at the speaker and community level, and ii) the extent to which a given innovation departs from the rules of the traditional norm (i.e. the variety of the minority language spoken by individuals who experience moderate or minimal levels of contact with the majority language). As we have seen, the relationship between these two factors can be summarized as follows: the more an innovation constitutes a departure from the rules of the traditional norm, the more likely its emergence will be limited to the speech of the speakers who exhibit the highest levels of contact; and conversely the more an innovation constitutes a minor departure from the rules of the traditional norm the more likely its emergence will be attested across a wide spectrum of speakers within the minority speech community (including those who exhibit only moderate contact).

18 The history of French in Canada and in Europe is replete with usages that started out as innovations rooted in contact with English and introduced by 'bilinguals' and that went on to spread to the rest of the community with subsequent loss of the initial association with bilingualism. Interestingly, the more recent history of Quebec French (i.e. after the 1970s) also features several cases where state intervention has had the effect of reversing the diffusion of contactinduced usages that were well integrated into the vernacular variety of Quebec French. Thus, it would seem that the diffusion of contactinduced innovations is primarily affected by extra-systemic factors whereas the emergence of innovations clearly involves a combination of systemic and extra-systemic factors.
Finally, even though all the innovations that we have examined represent a departure from the rules of the traditional norm, they are ultimately conditioned by the linguistic system of the minority language. Put differently, although the innovations under study are rooted in contact with English they do not represent the manifestation of erratic or baffling linguistic change. Indeed, for each of the innovations under study it is possible to argue that the influence of the majority language has been constrained by the structural properties of the minority language. Thus, even in the case of the most deviant of the eight innovations under study (i.e. the replacement of stative avoir by être followed by an 'Article-less Substantive') one can point to the constraining influence of internal factors. Specifically, as the copula etre is a logical alternative to stative avoir and since most substantives in French are preceded by an article, their use without an article to express a state makes them natural candidates for reanalysis as adjectives. Thus, a detailed analysis of innovations due to language contact leads one back to the task of accounting for the internal factors that may have favored the emergence of such innovations.

\section{References}

Coupier, C. (1983). L'emploi des pronoms personnels chez R'quia D. et Zahra K. In Acquisition du français par des travailleurs marocains (Papiers de travail 1, G.R.A.L.), pp. 19-36. Université de Provence.

Dubois, S. \& Noetzel, S. (2005). Intergenerational pattern of interference and internally-motivated changes in Cajun French. Bilingualism: Language and Cognition, 8(2), Special Issue: The role of transfer in language variation and change: Evidence from contact varieties of French,131143.

Fox, C. (2004). La restructuration grammmaticale en franco-américain. Paper given at Colloque international Grammaire comparée des variétés de français d'Amérique, Université d'Avignon, 16-20 May.

Grégoire, A. (1947). L'apprentissage du langage, II: La troisième année et les années suivantes. Paris: Les Belles Lettres.

Labov, W. (1972). Language in the inner city. Philadelphia: Pennsylvania University Press.

Milroy, J. (1992). Linguistic variation and change. Oxford: Blackwell.

Milroy, L. (1987). Observing and analyzing natural language. Oxford: Blackwell.

Mougeon, R. (2004). Perspective sociolinguistique sur le français en Ontario. In A. Coveney, A. Hintze \& C. Sanders (eds.), Variation et francophonie, pp. 155-190. Paris: L'Harmattan.

Mougeon, R., Bélanger, M. \& Canale, M. (1979). Le rôle de l'interférence dans l'emploi des prépositions en français et en anglais par des jeunes franco-ontariens bilingues. In M. Paradis (ed.), The Fourth LACUS Forum, pp. 550-559. Columbia, SC: Hornbeam Press, Inc. 
Mougeon, R. \& Beniak, E. (1991). Linguistic consequences of language contact and restriction: The case of French in Ontario. New York \& Oxford: Oxford University Press.

Mougeon, R. \& Beniak, É. (1995). Le non accord entre sujet et verbe en français ontarien: un cas de simplification? Présence francophone, 46, 53-66.

Mougeon. R. \& Rehner, K. (2001). Variation in the spoken French of Ontario French immersion students: The case of restrictive expressions and more. Modern Language Journal, 85 (3), 398-415.

Nadasdi, T. (2000). Variation grammaticale et langue minoritaire: le cas des pronoms clitiques en français ontarien. Munich: Lincom Europa.

Nadasdi, T. (in press). Le français en Ontario. In A. Valdman, J. Auger \& D. Piston-Hatlen (eds.), Le français en Amérique du Nord. Laval: Les Presses de l'Université Laval.

Nadasdi, T., Mougeon, R. \& Rehner, K. (2003). Emploi du «futur» dans le français parlé des élèves d'immersion française. Journal of French Language Studies, 13 (2), 195 219.

Pupier, P., Connors, K., Lappin, K. Greene, W. \& Nuckle, L. (1982). L'acquisition simultanée du français et de l'anglais chez des petits enfants de Montréal. Montreal: Office de la langue française.

Rehner, K. \& Mougeon. R. (1997). Use of restrictive expressions juste, seulement, and rien que in Ontario French. Journal of the Canadian Association of Applied Linguistics, 1, 89110.

Thibault, P. (1983). Equivalence et grammaticalisation. Ph.D. dissertation, Université de Montréal.

Vinet, M.-T. (1984). La syntaxe du québécois et les emprunts á l'anglais. Revue de l'Association québécoise de linguistique, 3, 221-242.

Received September 6, 2004

Accepted January 1, 2005 